\title{
Metadiscourse: Definitions, Issues and Its Implications for English Teachers
}

\author{
Mohammad Amiryousefi (corresponding author) \\ ACECR, Isfahan University of Technology, Isfahan, Iran \\ Tel: 98-091-3213-2381Ｅ-mail: M.Amiryousefi@Yahoo.com \\ Dr. Abbass Eslami Rasekh \\ Department of English, Faculty of Foreign Languages \\ University of Isfahan, Isfahan, Iran
}

Tel: 98-091-3110-3984_E-mail: Abbasseslamirasekh@Yahoo.com

\begin{abstract}
Metadiscourse is a new and interesting field of inquiry which is believed to play a vital role in organizing and producing persuasive writing, based on the norms and expectations of people involved. Metadiscourse embodies the idea that writing and speaking are more than just the communication of ideas and presentation of ideational meaning. Rather they are considered as social acts which involve writers, readers, speakers and listeners to interact with each other to affect the ways ideas are presented and understood. Metadiscourse is, therefore, believed to be an important feature of communication because we need to asses the readers' or listeners' resources for understanding the text and their likely responses to it in order to be able to write or to speak effectively. This article intends to study first, the definitions and issues of metadiscourse and then to introduce different metadiscourse signals and categorizations and examine the factors affecting their use, and finally to discuss metadiscourse in the classroom to demonstrate its values and implications for English teachers.
\end{abstract}

Keywords: Metadiscourse, Textual, Interpersonal, Metatext, Writer- reader interaction, Discourse community, Genre, Culture, Reading, Writing

\section{Introduction:}

Linguists' interest in discourse in recent years is gradually shifting from the traditional focus on ideational dimension of texts and speech to the ways they function interpersonally (Hyland, 2004).Such a view argues that writers or speakers do not simply produce a text to convey information and to represent an external reality. They, however, seek to ensure that the information they present is understandable and acceptable. In this regard, they draw their addressees in, and try to motivate them to follow along. To communicate effectively, they anticipate their receivers' expectations, requirements and resources, and try to engage them in their texts and affect their understandings of them. Writing or speaking is, therefore, viewed as a social and communicative process between writers or speakers and readers or listeners (Hyland and Tse, 2004; Hyland, 2004; Hyland, 2005).

Metadiscourse is a widely used term in current discourse analysis, and is a relatively new approach that refers to the ways writers or speakers project themselves in their texts to interact with their receivers. It is a concept which is based on a view of writing or speaking as a social engagement (Hyland, 2005; Dafouz-Milne, 2008).It is, therefore, believed to play an important role in organizing the discourse, engaging the audience and signaling the writer's or speaker's attitude (Fuertes-Olivera et al., 2001).As a result, it has been taken up and used by researchers to trace patterns of interaction, and to discuss different aspects of language in use.

The social perspective that metadiscourse entails has significant implications for language classes, and language teachers are gradually becoming aware of its significance. Until recently, language teachers focused on the content and how ideas were conveyed by speakers or writers, and writing was specially taught by just focusing on grammatical points or application of rules. Even today, these views still prevail and underlying rhetorical features and strategies are rarely taught (Mauranen, 1993; Hyland, 2005).

\section{Metadiscourse: definitions and issues}

"Metadiscourse embodies the idea that communication is more than just the exchange of information, goods or services, but also involves the personalities, attitudes and assumptions of those who are communicating"(Hyland,2005:3).Metadiscourse is "discourse about discourse" and refers to the author's or speaker's linguistic manifestation in his text to interact with his receivers (Vande Kopple,1985). For some scholars (e.g. Vande Kopple, 1985; Crismore et al., 1993) different levels of meaning can be found in a text; propositional and metadiscoursal. Vande Kopple (1985), for example, notes that:

Many discourses have at least two levels. On one level, we supply information about the subject of our text. On this level, we expand propositional content. On the other level, the level of metadiscourse, we do not add propositional 
material but help our receivers organize, classify, interpret, evaluate and react to such material. Metadiscourse, therefore, is discourse about discourse or communication about communication (p.83).

He further develops his discussion about the definition of metadiscourse, and explicitly makes the point that metadiscourse items are non-propositional, non-truth conditional:" They [metadiscourse items] do not expand the propositional information of the text. They do not make claims about states of affairs in the world that can be either true or false" (p. 85).This assumption about the non-truth conditional, non-propositional status of metadiscourse expressions can be seen in other recent works too. Crismore et al. (1993), for example, in their influential paper define metadiscourse as:" linguistic material in texts, written or spoken, which does not add anything to the propositional content but that is intended to help the listener or reader organize, interpret and evaluate the information given"(p.40). Similarly Hyland (1999) stresses non-propositionality of metadiscourse as follows:

"One important means by which texts depict the characteristics of an underlying community is through the writer's use of metadiscourse. All academic disciplines have conventions of rhetorical personality which influence the way writers intrude into their texts to organize their arguments and represent themselves, their readers, their attitudes. This is largely accomplished through non propositional material or metadiscourse (p. 5).

What remains difficult is how to make a distinction between metadiscourse and propositional content. Halliday (1994), for example, proposes the test of falsifiability to identify propositions. He states that "propositional material is something that can be argued about, affirmed, denied, doubted, insisted upon, qualified, tempered, regretted and so on" (Halliday, 1994:40 cited in Hyland and Tse, 2004:160). The picture is somehow clouded by Mao (1993:267 cited in Hyland, 2005:19). He believes that metadiscourse and proposional content can both be falsified. The picture, therefore, remains vague. Hyland (2005) draws on Myers (1990) who claims that academic papers are sometimes rewritten by the editorials for different audience. When it happens the content is the same, but the meaning may change drastically through re-textualization (Hyland, 2005, 21-22).He, therefore, concludes that "meaning of a text is not just the propositional material...It is the complete package"(p.22). By "complete package" he means both proposition and metadiscourse content, and he believes that metadiscourse is an essential and inseparable part of meaning. The point is that propositional-metadiscourse distinction is made for the sake of exploration and research (Hyland and Tse, 2004).

Another issue which is addressed in the literature of metadiscourse is if it is syntactic or functional. Adel (2006) believes that "metadiscourse is a functional category that can be realized in a great variety of ways"(p.22). She believes that an item which is metadiscursive in some point due to its relation with its co-text and its use, may not be metadiscursive in another (p.22-24).Hyland (2005) draws on the examples like the followings and states that text items are metadiscursive in relation to their co-texts.

A) I think she is crazy. First she screamed at me. Second she tore up the mail.

B) When I told her the news, first she screamed at me. Second she tore up the mail.

While the sequence markers (first and second) are used in A to list the arguments and to persuade the listener that the intended person is mad, in B they are used to unfold the experience (p.24-25).Adel (2006) and Hyland (2005) further argue that metadiscurse items may play different functions in different texts or even they may fill two or more functions at the same time.

\section{Textual and interpersonal functions of metadiscourse}

Halliday (1994) believes when people use language, they usually work toward fulfilling three macro functions. They try to give expression to their experience, to interact with their audience, and to organize their expressions into cohesive discourses. In other words, Halliday (1994) states that people communicate with messages that are integrated expressions of three different kinds of meaning; ideational, interpersonal, and textual:

- The ideational function: the use of language to represent experience and ideas. This roughly corresponds to the notion of propositional content.

- The interpersonal function: the use of language to encode interaction, allowing us to engage with others, to take on roles and to express and understand evaluations and feelings.

- The textual function: the use of language to organize the text itself, coherently relating what is said to the world and to the readers. (Halliday, 1994 cited in Hyland, 2005:26)

Hyland (1999) believes that "textual metadiscourse is used to organize propositional information in ways that will be coherent for a particular audience and appropriate for a given context"(p.7). He believes that the writer of a text predicts the receiver's processing difficulties and requirements, and accommodates them by using certain devices. He also states that interpersonal metadiscourse "allows writers to express a perspective toward their propositional information and their readers. It is essentially an evaluative form of discourse and expresses the writer's individually defined, but disciplinary circumscribed, persona" (p.7-8).

\section{Metadiscourse models}

Metadiscourse is essentially an open category which can be realized in numerous ways. There are huge range of linguistic items from punctuation and typographic markers (like parentheses and underlying) and paralinguistic cues which accompany spoken messages (like tone of voice and stress) to whole clauses and sentences which are used to 
reveal ourselves and our purposes in our texts(written or oral)(Hyland,1999,2005).A variety of metadiscourse taxonomies have, therefore, been proposed (Crismore, 1989; Vande Kopple, 1985, 2002; Hyland, 2005; Adel, 2006). The taxonomies which appear in Tables 1 to 4 demonstrate a theoretical fine-tuning as time develops.

The first model (Table1) was introduced by Vande kopple (1985).He introduced two main categories of metadiscourse, namely "textual" and "interpersonal". Four strategies-text connectives, code glosses, illocution markers and narrators- constituted textual metadiscourse, and three strategies-validity markers, attitude markers and commentaries-made up the interpersonal metadiscourse. Vande Kopple's model was specifically important in that it was the first systematic attempt to introduce a taxonomy that triggered lots of practical studies, and gave rise to new taxonomies. The categories are, however, vague and functionally overlap. Citation, for example, can be used to enhance a position by claiming the support of a credible other (validity markers). They can also be used to show the source of the information (narrators) (Hyland, 2005).

The revised model (Table.2) was introduced by Crismore et al. (1993). They kept the two major categories of textual and interpersonal, but collapsed, separated, and reorganized the subcategories. The textual metadiscourse was further divided into two categories of "textual" and "interpretive" markers in an attempt to separate organizational and evaluative functions. Textual markers consist of those features that help organize the discourse, and interpretive markers are those features used to help readers to better interpret and understand the writer's meaning and writing strategies (Crismore et al., 1993).

The model proposed by Hyland (2005), however, comprises of two main categories of "interactive" and "interactional". This model owes a great deal to Thompson and Thetela's conception (1995), but it takes a wider focus by including stance and engagement markers. The interactive part of metadiscourse concerns the writer's awareness of his receiver, and his attempts to accommodate his interests and needs, and to make the argument satisfactory for him. The interactional part, on the other hand, concerns the writer's attempts to make his views explicit, and to engage the reader by anticipating his objections and responses to the text (Hyland, 2005).

Most of the above models follow Halliday's (1994) tripartite conception of metafunctions which distinguishes between the ideational elements of a text-the ways we encode our experiences of the world-and its textual and interpersonal functions. Of course some others, like Adel (2006), do not follow Halliday's functions. She distinguishes between two main types of metadiscourse; "metatext" and "writer-reader interaction". Metatext spells out the writer's or reader's speech act. Writers may comment on their own discourse actions. They may, for example, introduce a topic, state an aim, or close the topic. Metatext can also represent the aspects of the text itself like its organization, wording, or the writing of it. Writer-reader interaction embodies those linguistic expressions which are used by the writer to engage the reader. These linguistic expressions like you might think or lets elaborate on it represent the writer's awareness of the existence of the reader and are exploited to interact with him (Adel, 2006:36-37).

\section{Factors affecting the use and distribution of metadiscourse markers}

\subsection{Metdiscourse and genre}

Writing is nowadays considered as a social engagement in which writers interact with their readers not only to convey messages, but also to help their receivers to understand them .It means that writers predict their readers' requirements and expectations, and respond to them. These expectations are within the bounds of their history; previous texts they have read, or the constrains of particular contexts. To communicate successfully, writers must recognize these bounds, forms and constrains, and get the things done through them (Hyland, 2005). Genre, therefore, refers to those conventionalized forms or moves which are associated with particular contexts that members of a community use to interact with each other (Swale,1990). To Swale (1990) as the pioneer of GA(genre analysis), genre is defined as communicative events specified by a series of communicative purposes and features recognized by the members of the community. Texts, accordingly, can be classified into one genre or another based on their key linguistic or rhetorical features. Metadiscourse is one such feature. Texts can be analyzed and classified based on different kinds of interactions they create with their readers, and different kinds of persuasion sought by writers or speakers. Evidentials, for example, can be used in an article to help the writer to relate his work to earlier or to other works in the field. They can, however, be used in an editorial to show the writer's seriousness 1 (Hyland, 2005: 87-89).Some kind of metadiscourse can be more appropriate than others-or even necessary-in some kinds of texts (Adel, 2006). These features can be drawn, classified and taught to students to enable them to write more effectively and persuasively.

\subsection{Metadiscourse and community}

Swales (1990:24-27) characterizes a discourse community as follows: It has a broadly agreed set of common public goals; has mechanism of intercommunication among its members; uses its participatory mechanisms primarily to provide information and feedback; utilizes and hence posses one or more genres in the communicative utterance of its aims; has acquired some specific lexis (specializes terminology); and has a threshold level of members with a 
suitable degree of relevant content and discoursal expertise. A discourse community, to put it in a simple term, refers to the people the text is aimed at (Barton, 1994:57). It is like a tribe with its own norms, categorizations and sets of conventions (Becher, 1989). Metadiscourse, accordingly, entails the fact that knowledge is the social justification of ideas, and writers must take into account their intended receivers' norms, expectations and responses which are embedded in the community they belong to, to construct a persuasive writing (Hyland,2005). Metadiscourse features are sensitive to these differences, and to teach students to write effectively largely depends on increasing their awareness of the existences of such differences in the use of metadiscourse markers.

\subsection{Metadiscourse and culture}

Williams (1983) maintains that culture has been one of the two or three most complex words in English. Culture has been viewed differently by different scholars, but the view which commands the most influence in language studies sees it as a historically transmitted and systematic patterns of meanings which allow us to understand, develop and communicate our knowledge and beliefs about the world (Lantolf, 1999).Cultural factors, therefore, shape our background understandings, and may affect the ways we write and the ways we organize our writing. Cultural values are carried by language and provide us with taken-for-granted ways of engaging others in writing. They can affect perception, language, learning, communication and particularly the use of metadiscourse (Hyland, 2005:113-115). "In a writer-responsible culture like English", for example, "metadiscourse markers are used to guide readers through a text; in a reader- responsible culture like Japanese, connections between various parts of a text are more commonly left implicit" (Adel, 2006:149). In English, therefore, the person responsible for effective communication is the writer, but in Japanese it is the reader. The difficulties of comprehension may be traced back to the amount of effort the writer may expect the reader to invest (Hyland, 2005). L1 and L2 writers may differ in preferred ways and patterns of organizing their ideas and engaging their readers, and these patterns tend to be transferred from native language to the foreign language (Chesterman, 1998). Each culture may have its own norms, values, language, as well as way of communication (van Dijk et al., 1997). What makes a written text well-organized and coherent is different across different cultures (Hyland, 2005). Contrastive studies on the use of metadiscourse can, consequently, help teachers to make students sensitive of the differences between students' national culture and the culture of the discourse or the community to which the text refers to (Hyland, 2005).

\section{Metadiscourse as an inseparable part of communication}

Metadiscourse, as discussed, is a central pragmatic construct which enables writers or speakers to interact with their receivers to achieve a successful communication (Hyland, 2004).It is, however, believed to be an integral part of text which can not be ignored or varied at will (Hyland, 1998). Hyland (1998) based on a textual analysis of 28 research articles in four academic disciplines acknowledged the importance of metadiscourse in attaining persuasion. The quantitative analysis of his study showed an average of 373 metadiscourse occurrence per paper; about one every 15 words. Hyland (1999) in his textual analysis of 21 textbooks in three disciplines found exactly the same results. The quantitative analysis revealed the importance of metadiscourse with an average occurrence of 405 per text; about one every 15 words. Hyland (2004), in a study on the distribution of metadiscourse in L2 postgraduate writing , revealed the importance of metadiscourse to students writing with an average occurrence of 184000 cases in 4 million words; one every 21 words. Its high occurrence, however, represents that it is an important part of communication without which the propositional and pragmatic content of utterances will be at danger (Abdi et al, 2009).

\section{Metadiscourse in the classroom}

\subsection{Metadiscourse and reading}

Reading process is considered to be a bottom-up, top-down interactive skill in which readers participate actively in the creation of meaning (Hadley, 2003). Effective comprehension is achieved when the reader alternates between bottom-up processing; encoding meaning from the print by paying careful attention to linguistic elements, and top-down processing whereby the reader activates his prior knowledge of content, and uses textual cues to cope with new information. Reading can, therefore, be seen as an "interactive" process between a reader and a text which leads to automaticity or reading fluency. In this process, the reader interacts dynamically with the text as s/he tries to elicit the meaning as he uses linguistic or systemic knowledge (through bottom-up processing) as well as schematic knowledge (through top-down processing) (Crismore 1989, Chastain,1988). Parallel to this interactive process between the reader and the content, there is also another important type of interaction: the one between the reader and the writer through an imaginary dialogue known as metadiscourse (Crismore 1989). The use of metadiscourse markers allows writers to intrude in their texts to signal their communicative intentions, and affect the ways these intentions are understood by their readers (Hyland, 1998). In L2 instructional contexts, students can understand how to interpret the author's communicative intentions and stance, and move along the text, and keep schemas and process the flow of information easily by raising their awareness of the presence and the functions of different 
metadiscourse markers representing the relations and functions of different parts of texts, author's attitudes, implicatures and presuppositions, shifts of topics, etc. (Crismore, 1989, Tavakoli et al., 2010).

7.2. Metadiscourse and writing

In the past writing was taught by either imitating sample works from experts or by focusing on elements and grammatical points, and the role of metadiscourse features was neglected. Even today theses views can be observed in writing classes. Explicit knowledge of grammar and application of rules are just one part of writing. The other part, however, is accommodating the ideas within the expectations and understandings of the relevant readers through the appropriate use of metadiscourse (Hyland,2005). We use metadiscourse when we filter our ideas through a concern with how our readers will take them. Metadiscourse is, therefore, the language we use when we refer to our own thinking and writing as we think and write-to summarize, on the contrary, I believe; to the structure of what we write-first, second, more importantly; and to our reader's act of reading-note that, consider now, in order to understand. We use metadiscourse to list the parts or steps in our presentation-first, second, third, finally; to express our logical connections- infer, support, prove, illustrate, therefore, in conclusion, however, on the other hand. We hedge how certain we are by writing-it seems that, perhaps, I believe, probably, etc (Vande Kopple, 1985; Crismore et al. 1985; Hyland, 2005; Adel, 2006). Unfortunately metadiscourse is not explicitly taught, and students often have considerable trouble to flesh out an image of their readers and to interact properly with them. They may, for example, inadequately overuse boosters (like no doubt, easily see, will see) and engagement markers (like we, you) and turn a formal academic writing to an informal and direct argument. It is, therefore, essential that students receive appropriate instruction in metadiscourse using models of argument to practice writing within the norms and socio-cultural limitations of their readers (Hyland, 2005:175-178).

\subsection{Advantages of teaching metadiscourse features}

Hyland (2005) believes that there are three main advantages of teaching metadiscourse features to students. First, they can recognize the cognitive demands that texts make for readers, and the ways they can help them to proceed. Second, it provides them with enough resources to take a stance toward their ideas. Third, it enables them to negotiate that stance with their readers. Highlighting metadiscourse in the classroom can have other advantages and contributions such as: providing a context to place propositional information; increasing the persuasiveness of a text; improving comprehension and recall; assisting coherence and relating issues clearly to each other; highlighting the writer's uncertainties and positions on the propositional information in a text, and making readers aware of the subjective interpretation of truth; indicating writer's attitudes to the reader and the text, and his attempts to relieve the reader's processing load by highlighting important points, linking sections and ideas, etc. (Hyland, 2005:178-179).

\subsection{Principle sand strategies of teaching metadiscourse features}

Teaching metadiscourse means sensitizing students to rhetorical effects and features that exist within a given genre and community, and equip them with enough resources to interact with their readers in their own world (Swales, 1990; Hyland, 2005). To teach metadiscourse features appropriately, teachers need to 1) understand their students' target needs; for what purposes they are learning to write and to whom they will interact. Based on the analysis of their needs, they can provide their students with opportunity to explore the ways writers use metadiscourse in the given genre and community; 2) consider the students' prior writing and learning experiences. Students may bring to the class different culturally grounded writing conventions which may be different from their readers'; 3 ) view learning to write as learning to use language. They need to encourage their students to see the target language as a way of meaning making and interaction with their readers, and stress the importance of such interactions by teaching them how certain devices can be exploited to construct such interactions and dialogues with readers. To do so teachers need to incorporate a range of real and simulated audience sources into their classes. These sources can be real readers, student peers or the teachers; 4) use authentic texts and expose their students to the most productive and frequently used metadiscourse features to make them familiar with their use and functions. Familiarizing students with metadiscourse can begin with the task of analyzing these authentic texts to see how metadiscourse markers are used in the relevant context; 5) provide students with the tasks of manipulating and producing texts. After students are given opportunities to analyze and identify metadiscourse features in relevant authentic texts, teachers should provide students with focused activities like editing a draft text or completing a text in which certain metadiscourse markers are missing to develop their confidence, and to let them see the effects of different metadiscourse features on such texts. Finally students should be provided with actual writing situations to actually use and test their knowledge and understandings of metadiscourse (Hyland, 2005:181-193).

\subsection{Data representing usefulness of teaching Metadiscourse strategies}

Some studies have suggested that communication abilities of students are enhanced through explicit teaching of metadiscourse strategies. Jalilfar and Alipour 's study (2007), for example, on the effects of explicit teaching of metadiscourse markers to pr-intermediate Iraninan EFL learners' reading skill revealed the positive influence of 
form-focused instruction of metadiscourse. Parvaresh (2008), moreover, investigated the effects of metadiscourse markers on the comprehension of English texts. The results revealed the positive effects of teaching metadiscourse especially for lower proficiency learners. The results also showed that the difficulty, in the sense of being able to comprehend the major points of the texts, was closely related to the presence or absence of metadiscourse. These findings are further proved by Tavakoli et al.'s study on the effects of explicit teaching of metadiscourse on intermediate students' reading comprehension. Their study revealed that: "1) Instruction on metadiscourse influenced the subjects' consciousness efficiently so as to boost their ability of reading comprehension, and thus led to their significant performance on the post-test. 2) Although instruction on all metadiscourse markers affected the subjects' performance, awareness on textual markers seemed to be note-worthy in relation to interpersonal ones.3) From the overall findings, it can be figured out that instruction on metadiscourse awareness not only affected the subjects' performances on reading comprehension, but also enhanced their achievement in all aspects of L2 focused during the course of experiment" (Tavakoli et al., 2010:98).

Other studies focusing on the writing abilities of the students have also proved the usefulness of teaching metadiscourse strategies. Cheng and Steffensen (1996), for example, discovered that the group that received instructions on the functions and use of metadiscourse got higher grades in their essays. Shaw and Shaw and Lieu (1998) also found substantial improvements in students' essay writing after two month of EAP instruction including metadiscourse strategies. Through increasing their awareness of genre expectations and audience interaction, an increased use of transitions and engagement markers and a decrease in self- mention was reported regarding the use of metadiscourse features. Sengupta (1999) found almost the same results. She examined how rhetorical consciousness raising influenced students' reading and writing. The participants were 15 Chinese Year-1 BA students and rhetorical consciousness was developed through regular discussions regarding the features of texts including metadiscourse markers. The results showed that they effectively used metadiscourse strategies taught to get the gist of the text read and to make their own writing more reader-friendly. Martinez (2004), moreover, investigated the relationship between the number of metadiscourse markers and the students' scores on their compositions. The results showed that there was a positive relation between the highly rated essays and the number of metadiscourse markers used.

\section{Conclusion}

Metadiscourse is based on a view of writing as a social interaction, and reveals the ways writers and readers interact with each other within the text. As we speak or write we negotiate with others, making decisions about the kinds of effects we want to have on our readers and listeners (Hyland and Tse, 2004).There are different metadiscourse taxonomies and classifications available in the literature. Theses taxonomies have improved theoretically and functionally with time and practice. The one proposed by Hyland is, however, the most widely used by different scholars. There are a range of factors such as genre, discourse community and culture which affect metadiscourse use and distribution which need to be taken into account by teachers, students and novice readers and writers. Despite rich literature, metadiscourse has failed to achieve considerable attention and interest by teachers and applied linguists. Until recently, teachers have been busy analyzing and instructing linguistic elements and grammatical rules to their students as discrete points and have not spent enough energy on the rhetorical parts of speech and texts. The importance of metadiscourse is gradually becoming recognized in language classroom and a number of studies are done on the effects of teaching metadiscourse markers on some language skills like reading, writing and listening. These studies reveal the significance of teaching metadiscourse markers to improve students' communication abilities.

\section{References}

Abdi,R., Tavangar Rizi,M. \& Tavakoli,M.(2009). The cooperative principle in discourse communities and genres: A framework for the use of metadiscourse. Journal of Pragmatics (2009), doi:10. 1016/j.pragma.

Adel, A. (2006). Metadiscourse in L1 and L2 English. Philadelphia: John Benjamins.

Barton, D. (1994). Literacy: An Introduction to the Ecology of Written Language. Oxford: Blackwell.

Becher,T.(1989). Academic Tribes and Territories: Intellectual Inquiry and the Culture of Disciplines. Milton Keynes: SRHE/OUP.

Chastain, K. (1976). Developing Second Language Skills: Theory to Practice (2 ${ }^{\text {nd }}$ Ed.). Chicago: Rand McNally College.

Cheng,X.\& Steffensen,M.(1996). Metadiscourse: A technique for improving student writing. Research in the Teaching of English, 30, 149-181

Chesterman,A.(1998). Contrstive Functional Analysis. Amesterdam and Philadelphia: John Benjamin Publishing Company.

Crismore, A., Markkanen R., \& Steffensen, M. (1993) . Metadiscourse in persuasive writing: a study of texts written by American and Finnish university students. Written Communication, 10, 39-71. 
Crismore, A.( 1989). Talking with Readers: Metadiscourse as Rhetorical Act. New York: Peter Lang Publishers.

Dafouz-Milne,E.(2008). The pragmatic role of textual and interpersonal metadiscourse markers in the construction and attainment of persuasion:A cross-linguistic study of newspaper discourse. Journal of Pragmatics, 40,95-113.

Fuertes-Olivera, P.A.,Velasco-sacristan,M.,Arribas-Bano,A. \& Samaniego-Fernandez,E.(2001). Persuasion and advertising English: Metadiscourse in slogans and headlines. Journal of Pragmatics, 33, 1291-1307.

Hadley, A.O. (2003). Teaching Language in Context. USA: Heinle \& Heinle.

Halliday, M.A.K. (1994). An Introduction to Functional Grammar $\left(2^{\text {nd }}\right.$ ed.). London: Edward Arnold. Cited in Hyland, K. (2005).

Hyland,K.(1999).Talking to students: Metadiscourse in introductory course books. English for Specific Purposes, 18, 3-26.

Hyland, K. (1998). Persuasion and context: The pragmatics of academic metadiscourse. Journal of Pragmatics, 30,437-455.

Hyland,K.(1999).Talking to students: Metadiscourse in introductory course books. English for Specific Purposes, 18(1),3-26.

Hyland, K. (2004). Patterns of engagement: Dialogic features and L2 student's writing. In L. Ravelli \& R. Ellis (eds.), Academic Writing in Context: Social-functional Perspectives on Theory and Practice. London: Continuum.

Hyland, K., \& Tse, P. (2004). Metadiscourse in academic writing: A reappraisal. Applied Linguistics, 25(2), 156-177.

Hyland,K.(2004). Disciplinary interactions: Metadiscourse in L2 postgraduate writing. Journal of Second Language writing, 13, 133-151.

Hyland, K. (2005). Metadiscourse: Exploring Interaction in Writing. London: Continuum.

Jalilfar,A.\& Alipour,M.(2007).How explicit instruction makes a difference: Metadiscourse markers and EFL learners' reading comprehension skill. Journal of College Reading and Learning, 38.

Lantolf,J.P.(1999). Second Culture Acquisition: Cognitive Considerations. In E. Hinkel (ed.),Culture in Second Language Teaching and Learning. Cambridge: CUP.28-46.

Martinez,A.C.L.(2004). Discourse markers in the expository writing of Spanish university students .IBERICA,8,63-80.

Mauranen,A.(1993). Cultural Differences in Academic Rhetoric: A Textlinguistic Study. Frankfort am Main:Peter Lang Publisher.

Mao,L.(1993). I conclude not: Toward a pragmatic account of metadiscourse. Rhetoric Review, 11(2), 265-289.Cited in Hyland,K.(2005).

Myers,G.(1990). Writing Biology: Texts in the Social Construction of Scientific Knowledge. Madison: University of Wisconsin Press.

Parvaresh, V.(2008). Metadiscourse and reading comprehension: The effects of language and proficiency. Electronic Journal of Foreign Language Teaching , 5( 2), 220-239

Sengupta, S.(1999).Rhetorical consciousness raising in theL2 reading classroom. Journal of Second Language Writing, 8(3), 291-319.

Shaw, P. \& Liu,E.(1998). What develops in the development of second language writing. Applied Linguistics, 19(2),225-254.

Swales, J. M. (1990). Genre Analysis: English for Specific Purpose in Academic and Research Setting. New York: Cambridge University Press.

Tavakoli,M.,Dabaghi,A., \& Khorvash,Z.(2010). The effect of metadiscourse awareness on L2 reading comprehension: A case of Iranian EFL learners. Ccsenet: English Language Teaching Journal, 3(1), 92-102.

Thompson, G., Thetela, P. (1995). The sound of one hand clapping: the management of interaction in written discourse. TEXT 15 (1), 103-127.

Vande Kopple, W. J. (1985). Some explanatory discourse on metadiscourse. College Composition and Communication 36, 82-93.

Vande Kopple, W. J.(2002). Metadiscourse, discourse, and issues in composition and rhetoric. In F.Barton \& C.Stygall (eds.), Discourse studies in composition. Cresskill, NJ: Hampton Press.91-113.

van Dijk, T. A., Ting Toomy, S., Smitherman, G., \& Troutman, D. (1997). Discourse, Ethnicity, Culture and Racism. In: van Dijk, T. (ed.), Discourse as Social Action. London: Sage Publications.

Williams, R. (19883).Keywords: A Vocabulary of Culture and Society. New York: OUP. 
Table 1. Vande Kopple's Classification System for Metadiscourse(1985,pp.82-92)

\begin{tabular}{|c|c|}
\hline Category & Function \\
\hline \multicolumn{2}{|l|}{$\begin{array}{l}\text { Textual } \\
\text { metadiscourse }\end{array}$} \\
\hline Text connectives & $\begin{array}{l}\text { Used to help show how parts of a text are connected to one another. Includes sequencers (first, next, in the second place), } \\
\text { reminders (as I mentioned in chapter 2), and topicalizers, which focus attention on the topic of a text segment (with regard } \\
\text { to, in connection with). }\end{array}$ \\
\hline Code glosses & $\begin{array}{l}\text { Used to help readers to grasp the writer's intended meaning. Based on the writer's assessment of the reader's knowledge, } \\
\text { these devices reward, explain, define, or clarify the sense of a usage }\end{array}$ \\
\hline Validity markers & $\begin{array}{l}\text { Used to express the writer's commitment to the probability of or truth of a statement. These include hedges(perhaps, } \\
\text { might, may), emphatics(clearly, undoubtedly), and attributers which enhance a position by claiming the support of a } \\
\text { credible ot5her(according to Einstein) }\end{array}$ \\
\hline Narrators & $\begin{array}{l}\text { Used to inform readers of the source of the information presented- who said or wrote something (according to smith, the } \\
\text { Prime minister announced that). }\end{array}$ \\
\hline \multicolumn{2}{|l|}{$\begin{array}{l}\text { Interpersonal } \\
\text { metadiscourse }\end{array}$} \\
\hline Illocution markers & $\begin{array}{l}\text { Used to make explicit the discourse acts the writer is performing at certain points(to conclude, I hypothesize, to sum up, } \\
\text { we predict) }\end{array}$ \\
\hline Attitude markers & $\begin{array}{l}\text { Used to express the writer's attitudes to the propositional material he or she presents9unfortunately, interestingly, I wish } \\
\text { that, how awful that). }\end{array}$ \\
\hline commentaries & $\begin{array}{l}\text { Used to address readers directly, drawing them into an implicit dialogue by commenting on the reader's probable mood or } \\
\text { possible reaction to the text(you will certainly agree that, you might want the third chapter first). }\end{array}$ \\
\hline
\end{tabular}

Table 2. Metadiscourse Categorization by Crismore et al. (1993, pp.47-54)

\begin{tabular}{|l|l|l|}
\hline Category & Function & Examples \\
\hline Textual metadiscourse & & \\
\hline Logical connectives & & \\
\hline Sequencers & Show connection between ideas & Therefore; so; in addition; and \\
\hline Reminders & Indicate sequence /ordering of material & First; next; finally; $1,2,3$ \\
\hline Topicalizers & Refer to earlier text material & As we saw in chapter one \\
\hline 2.Interpretive markers & Indicate a shift in topic & Well, now we discuss ... \\
\hline Code glosses & & \\
\hline Illocution markers & Explain text material & For example; that is \\
\hline Announcements & Name the act performed & To conclude; in sum; I predict \\
\hline Interpersonal metadiscourse & Announce upcoming material & In the next section \\
\hline Hedges & & \\
\hline Certainty markers & Show uncertainty to the truth of assertion & Might; possible; likely \\
\hline Attributers & Express full commitment to assertion & Certainly; know; shows \\
\hline Attitude markers & Give source/support of information & Smith claims that ... \\
\hline Commentary & Display writer's affective values & I hope/agree; surprisingly \\
\hline
\end{tabular}


Table 3. An Interpersonal Model of Metadiscourse (Hyland, 2005, p.49)

\begin{tabular}{|l|l|l|}
\hline Category & Function & Examples \\
\hline Interactive & Help to guide the reader through the text & Resources \\
\hline Transitions & Express relations between main clauses & In addition; but; thus; and \\
\hline Frame markers & Refer to discourse acts, sequences and stages & Finally; to conclude; my purpose is \\
\hline Endophoric markers & Refer to information in other parts of the text & Noted above; see figure; in section 2 \\
\hline Evidentials & Refer to information from other texts & According to X; Z states; \\
\hline Code glosses & Elaborate propositional meaning & namely; e.g.; such as; in other words \\
\hline Interactional & Involve the reader in the text & Resources \\
\hline Hedges & Withhold commitment and open dialogue & Might; perhaps; possible; about \\
\hline Boosters & Emphasize certainty and close dialogue & \\
\hline Attitude markers & Express writer's attitude to proposition & Unfortunately; I agree; surprisingly \\
\hline Self-mentions & Explicit reference to authors & I; we; my; me; our \\
\hline Engagement markers & Explicitly build relationship with reader & Consider; note; you can see that \\
\hline
\end{tabular}

Table 4. Personal and impersonal configurations of metatext and writer-reader interaction (Adel, 2006:38)

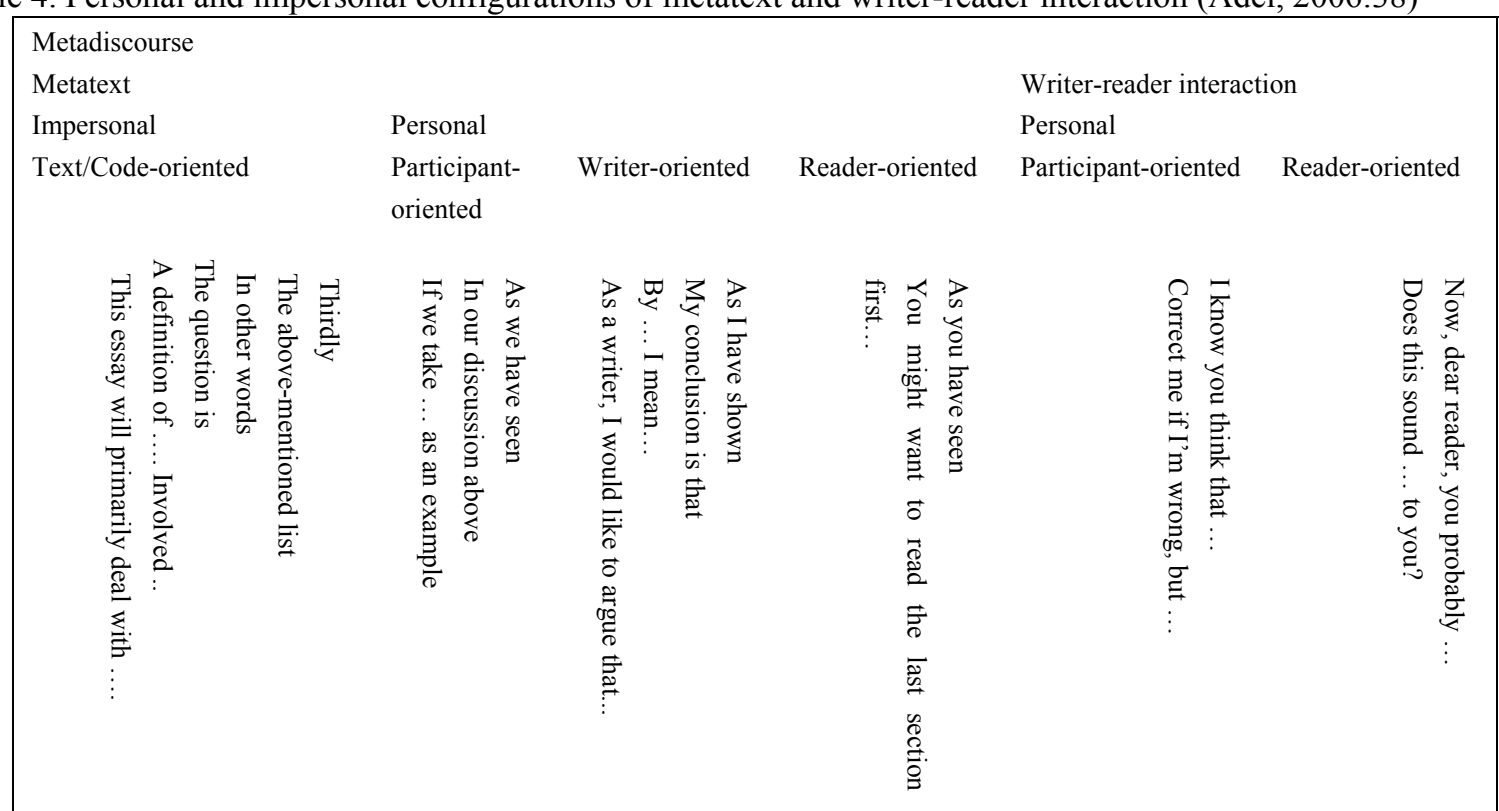

